Cena, baile y muerte: cotidianidad y administración de justicia en Popayán durante la restauración monárquica, 1815-1819

Dinner, Dance, and Death: Everyday life and the Administration of Justice in Popayán during the Restoration of Monarchical Rule, 1815-1819

Dîner, danse et mort : vie quotidienne et administration de justice à Popayán pendant la Restauration monarchique, 1815-1819

Ángela Pérez Villa

\title{
OpenEdition
}

Journals

Edición electrónica

URL: http://journals.openedition.org/rhj/7437

DOI: $10.4000 /$ rhj.7437

ISSN: 0719-4153

Editor

ACTO Editores Ltda

Referencia electrónica

Ángela Pérez Villa, «Cena, baile y muerte: cotidianidad y administración de justicia en Popayán durante la restauración monárquica, 1815-1819 », Revista Historia y Justicia [En línea], 15 | 2020, Publicado el 30 noviembre 2020, consultado el 10 diciembre 2020. URL : http:// journals.openedition.org/rhj/7437 ; DOI : https://doi.org/10.4000/rhj.7437

Este documento fue generado automáticamente el 10 diciembre 2020.

Revista Historia y Justicia 


\section{Cena, baile y muerte: cotidianidad y administración de justicia en Popayán durante la restauración monárquica, 1815-1819}

Dinner, Dance, and Death: Everyday life and the Administration of Justice in Popayán during the Restoration of Monarchical Rule, 1815-1819

Dîner, danse et mort : vie quotidienne et administration de justice à Popayán pendant la Restauration monarchique, 1815-1819

Ángela Pérez Villa

\section{NOTA DEL EDITOR}

Recibido : 09 de abril de 2020 / Aceptado: 20 de julio de 2020

\section{Introducción}

1 A principios de julio de 1815, en el auge de las guerras de independencia en la Nueva Granada, los patriotas lograron una de sus más grandes victorias al derrotar al ejército realista en la batalla del Río Palo en la provincia de Popayán. Soldados e historiadores revolucionarios de la época registraron la hazaña en sus escritos y memorias con palpable fervor. José María Espinosa, artista y soldado patriota que participó en la campaña, escribió por ejemplo que fue tal el "ánimo y ardor" exhibido por él y sus compañeros en batalla, "que en poco tiempo quedaron arrollados y desechos los batallones realistas". Además, añadió que esta batalla sería recordada como "una de las más notables y reñidas de aquella época, y de las más importantes por sus consecuencias, pues por entonces quedó pacificado el Cauca y libre de enemigos"1. 
2 De igual forma, el historiador revolucionario José Manuel Restrepo, subrayó en su narración de los hechos cómo la "mucha intrepidez" de las tropas independentistas debilitó a las fuerzas realistas al punto que "muy pocos soldados y algunos oficiales enemigos pudieron escapar" . A pesar del cuestionable carácter propagandista que tiñó estas y otras descripciones de la batalla, la derrota del ejército realista fue significativa por haber coincidido con el arribo del capitán Pablo Morillo, general militar del reino de España, y su Ejército Pacificador a territorio neogranadino. Morillo comandaba el regreso de las tropas del rey Fernando VII con el fin de restablecer el mando de la corona a través de una agresiva campaña militar que posteriormente conoceríamos en la historiografía colombiana como la Reconquista española o, más recientemente, como la Restauración monárquica ${ }^{3}$.

3 En el marco de la restauración liderada por Morillo, los realistas de Popayán conseguirían fortalecer sus tropas. Con ello, en cuestión de un año pusieron en marcha un exitoso contraataque. Sin embargo, mientras transcurría ese tiempo: ¿Qué ocurrió con aquellos soldados que sobrevivieron a la batalla del Río Palo y lograron escapar? ¿Cómo se integraron a la vida cotidiana en sus localidades en medio del inminente recrudecimiento de la guerra durante la restauración? ¿Qué complejidades revelan las relaciones interpersonales entre soldados y la gente del común sobre las dinámicas sociales y legales que regían en la época? Son pocos los estudios sobre este periodo (1815-1819) y aún menos los que consideran las dimensiones históricas que permiten responder a este tipo de preguntas. Esto se debe, en general, a que como argumenta Daniel Gutiérrez Ardila, "la historiografía ha sido reacia a estudiar, a espulgar, a enunciar y a juzgar, intimidada por un poderoso relato broncíneo" ${ }^{4}$, que ha perpetuado la visión pomposa de los patriotas sobre aquel tiempo.

El presente artículo coincide con esa postura y propone dirigir la mirada al archivo judicial en busca de documentación cuya lectura analítica amplíe y complejice nuestro entendimiento sobre el periodo. Este artículo considera entonces las preguntas anteriores desde una óptica judicial, concentrándose en desmenuzar un nutrido caso criminal contra un soldado realista con el fin de ahondar en la relación entre la cotidianidad y los procesos de justicia en un periodo de profunda agitación política. Este abordaje no supone una oposición entre vida cotidiana y guerra. Al contrario, se entiende que el contexto de guerra enmarca la cotidianidad, reflejando las interdependencias entre lo militar, lo social y lo legal durante este periodo. El soldado protagonista del caso era Lucas Ballesteros, un hombre de sesenta años, de calidad montañés, casado y vecino de la ciudad de Popayán que fue preso por haber dado muerte a Joaquín Tenorio, un hombre negro libre, días después de culminada la batalla del Río Palo.

Durante los tres años que permaneció activo el caso, Ballesteros nunca negó haber causado la muerte del negro Joaquín Tenorio. Desde prisión, Ballesteros no solo describió en sus interrogatorios las circunstancias que le llevaron a cometer el crimen (corroboradas por cuatro testigos presenciales), sino que en las cartas que envió pidiendo su excarcelación a las autoridades encargadas del caso, también relató sus problemas de salud y sus memorias del servicio que prestó como chasqui al ejército realista. Claramente, al abogar por sí mismo, Ballesteros registró sus anécdotas y perspectivas con el fin de crear una imagen que generara compasión y que minimizara o eliminara su castigo. En este sentido, la producción narrativa en los casos judiciales aparece teñida y parcializada, pero no por esto debe descalificarse. Los detalles 
proporcionados por Ballesteros, junto con los relatos y acciones de los testigos, autoridades y la viuda del muerto, generan preguntas y agregan una riqueza excepcional al expediente que merece ser estudiada.

6 Es así como este artículo utiliza las disposiciones de Ballesteros y demás documentos presentes en el expediente judicial para crear un marco narrativo cronológico entre 1815 y 1818, bajo el cual se retratan las peripecias de un soldado realista y se reconstruye una imagen de la cotidianidad que nos permite reconocer que, durante la restauración monárquica, la gente del común en Popayán pasaba sus días cultivando la tierra, vendiendo en los mercados, viajando entre el campo y la ciudad, lidiando con las tensiones de la vida marital, realizando transacciones y en sus ratos libres, festejando de manera improvisada la camaradería y, por qué no, la vida ${ }^{5}$. Más allá de esto, la lectura crítica del expediente deja ver que las autoridades no limitaron la participación de mujeres en los procesos judiciales durante este tiempo. En este caso se puede ver intermitentemente a la viuda exigiendo justicia para el negro Tenorio y castigo para Ballesteros y sus cómplices. Sin embargo, como se mostrará, esa capacidad de acción pareció estar sujeta a las prioridades de las autoridades al mando del sistema judicial.

Este artículo comienza con una discusión sobre el uso de la documentación judicial en la reconstrucción de la historia de la Nueva Granada, seguido por secciones que retratan críticamente los hechos registrados en el expediente judicial. A través de una lectura minuciosa y crítica, se presta atención a los detalles, construyendo un análisis que por momentos se entrecruza con otras fuentes históricas relevantes o temáticas que pueden ampliarse con el fin de resaltar el potencial de las fuentes en el trabajo histórico.

\section{La documentación judicial en la reconstrucción histórica}

En los últimos 25 años, la documentación judicial ha sido cada vez más utilizada como fuente para el análisis histórico de la época colonial en Colombia. La investigación que abrió el camino para ello fue la de Beatriz Patiño, quien identificó y analizó tendencias generales sobre la criminalidad y la administración de justicia en la provincia de Antioquia a fines de la colonia ${ }^{6}$. A través de un análisis cuantitativo de casos por injuria y homicidio, Patiño demostró cómo las autoridades aplicaron la ley y ejercieron el poder del Estado colonial para controlar a la población y castigar a quienes tuvieran problemas con la justicia. Además, Patiño advirtió sobre las limitaciones de las fuentes judiciales y sugirió que la riqueza de algunos de los juicios criminales ameritaba una atención más detallada por parte de futuros investigadores ${ }^{7}$. La historiografía ha registrado desde entonces la aparición de trabajos que, basados en fuentes judiciales, han estudiado la aplicación de la ley en múltiples facetas de la cotidianidad ${ }^{8}$ familiar entre los sectores populares durante la colonia, tales como las relaciones maritales y extramaritales, los procesos por alimentos, la ilegitimidad, la vagancia y la violencia doméstica9.

9 Entre estas investigaciones, la de Catalina Villegas del Castillo expone que la ausencia de expedientes judiciales por asuntos familiares durante el periodo independentista en el Archivo Nacional de Colombia constituye un "silencio documental" que complica el entendimiento sobre la administración de la justicia en tiempos de guerra ${ }^{10}$. Según la autora, entre las distintas razones que podrían explicar ese silencio están la posible 
desorganización del sistema judicial en un periodo de caos y un cambio constante de prioridades que llevó a las autoridades a prestar más atención a los juicios políticos contra opositores e insurgentes como táctica de guerra ${ }^{11}$. Sea cual sea la razón, la limitación de ese silencio documental no le impidió a la autora acudir al cruce de fuentes para analizar distintos hechos y circunstancias que le permitieran retratar procesos de ruptura y continuidad en el tránsito de la colonia a la república. A pesar del aporte de este tipo de investigaciones, persiste una laguna histórica con relación a la dimensión sociocultural y legal durante los años de las guerras de independencia (1810-1820) ¿Sería posible confrontar ese silencio consultando en los archivos regionales? ¿Cuál sería el efecto de reducir la escala de observación temática y temporal con el fin de detectar indicios? ¿Podríamos entonces comenzar a reconstruir el entramado social y legal en tiempos de guerra?

El Archivo Central del Cauca en la ciudad de Popayán es un archivo regional que conserva la memoria documental de la época de las guerras de Independencia en el suroccidente colombiano. La documentación judicial que existe de ese periodo en particular contiene una riqueza material y de contenido invaluable que, examinada con herramientas analíticas críticas, revela las relaciones intrincadas entre la vida íntima, social y legal. En particular, los expedientes sobre ofensas verbales, riñas, homicidios y hasta delitos sexuales que reposan en el archivo retratan no solo las complejas relaciones entre los habitantes de Popayán, también muestran la improvisación de las autoridades, sin importar su filiación ideológica, en la interpretación y aplicación de la ley en momentos de abruptos y violentos cambios políticos y constante transición. Aunque algunos expedientes son más largos y completos que otros, en general, el carácter fragmentario de estas fuentes abre ventanas para profundizar en el análisis microhistórico ${ }^{12}$.

11 Este artículo pone en marcha algunas de las herramientas analíticas propias de la microhistoria como la lectura minuciosa, crítica y entre líneas, con el fin de comenzar a reconstruir la historia más allá de las confrontaciones militares y políticas que tanto han dominado las narrativas convencionales sobre el periodo independentista y, en especial, sobre la restauración en la Nueva Granada. Partiendo de esta idea, se considera que los episodios descritos en la documentación judicial, con todo y sus limitaciones, ayudan a desentrañar la compleja y conflictiva red de relaciones sociales y jurídicas que definieron el día a día en Popayán en el marco de la restauración monárquica. Se analiza entonces un solo expediente, no por su singularidad, sino por la enorme riqueza descriptiva que contienen sus apartes y la oportunidad que brinda para conectar, interrogar y/o especular. No se pretende totalizar la historia social de la época de la restauración en Popayán con base exclusivamente en este caso. Por el contrario, se busca mostrar el potencial que estas fuentes ofrecen para penetrar el mundo cotidiano y judicial que existió en ese tiempo.

\section{Fiesta y prisión}

\subsection{Festejo y bebida en una noche de 1815}

El 5 de febrero de 1818, el soldado Lucas Ballesteros envió desde prisión en Popayán una carta pidiendo indulto al español José Solís, gobernador realista de la provincia del Cauca. En tres páginas, Ballesteros narró los acontecimientos que le llevaron a prisión 
después de la batalla del Río Palo y las circunstancias que llevaba padeciendo por el deterioro de su salud y porque su caso no había sido resuelto aún tres años después del crimen. Tras haber sobrevivido a la derrota de los realistas en 1815, Ballesteros contó que se marchó a continuar su vida por los lados de Cajibío, una pequeña parroquia al norte de la ciudad de Popayán, y pocas semanas después, el 21 de julio, coincidió con un grupo de gente en casa del indio Domingo Mambuscay. En ese grupo estaban Manuela Vega y su esposo "el negro" Joaquín Tenorio a quienes Ballesteros conocía, según él, "meramente de saludación" ${ }^{13}$. Ballesteros relató que después de compartir una noche de tragos y de embriagarse entró en una "batalla de manos de hombre a hombre" con Tenorio. Según él, Tenorio lo atacó sin motivo y él, para defenderse, terminó por herir de muerte a Tenorio en el pecho con su propio cuchillo ${ }^{14}$. Por este motivo dijo que fue arrestado y encarcelado mientras las autoridades hacían sus respectivas investigaciones.

13 En esta versión de los hechos, Ballesteros claramente se situó así mismo en una posición de inocencia y desventaja con relación a Tenorio, quizá con la intención de hacer ver que su forma de actuar fue en defensa propia. Esta posición fue la misma que sostuvo en los dos interrogatorios que tuvo durante el proceso. Como es de esperarse, esta versión distaba de la de los testigos citados a declarar. De siete testigos que se presentaron, dos no habían estado en el festejo, pero querían aprovechar las circunstancias para acusar formalmente a Ballesteros de intimidación y amenazas de muerte en otros momentos de socialización que tuvieron en el campo. Ballesteros negó las acusaciones, pese a que los dos testigos ratificaron sus declaraciones en tres ocasiones distintas. Por su parte, cuatro testigos presenciales en la muerte de Tenorio declararon, incluyendo la viuda Manuela Vega. Manuela era una mujer de más de veinticinco años, analfabeta y vendedora de comida que vivía en la ciudad de Popayán. Ella testificó ante el alcalde ordinario de Popayán, doctor don Matías de Belalcázar Fajardo, sobre los eventos que, en su perspectiva, condujeron a la muerte de su esposo esa trágica noche de julio.

14 Manuela declaró que a fines del mes de julio compró una carga de guarapo al indio Domingo, quien viajaba una vez por semana desde Cajibío a la ciudad de Popayán para vender plátanos y guarapo en el mercado central ${ }^{15}$. Después de realizar la compra, Manuela ordenó a Domingo dos cargas extras de guarapo y acordó recogerlas en la casa de él al final de la semana. Días después, cuando caía la tarde del viernes, Manuela y su esposo se presentaron en casa de Domingo para recoger las cargas de guarapo, pero él se encontraba en el trapiche. Decidieron esperarlo junto con otras tres personas que también buscaban a Domingo para hacer negocios: Lucas Ballesteros, María Jesús Orbea alias Ratona y un joven negro esclavizado al que Manuela identificó como "mulatico Isidro"16. Cuando Domingo regresó a casa invitó a todos sus visitantes a quedarse a cenar. La invitación pronto se convirtió en una fiesta improvisada cuando la comadre de Domingo sirvió guarapo de cortesía para todos los asistentes, quienes luego pagaron a Domingo para que sirviera más y pudieran continuar con el festejo ${ }^{17}$. Para animar la celebración, Domingo comenzó a tocar su guitarra, Joaquín el alfandoque ${ }^{18}$ e Isidro el zumbo $^{19}$. Manuela y la comadre de Domingo observaban el jolgorio, mientras que Lucas y Ratona bailaban al son de la música de aquellos instrumentos. El canto de Joaquín se extendió hasta altas horas de la noche.

15 La narración de Manuela sobre una noche de diversión con un grupo diverso de gente que incluía negros, mestizos, indígenas y blancos pobres fue corroborada por los otros 
tres testigos presenciales que testificaron en el caso. Todos recalcaron el ambiente festivo que se vivió esa noche gracias a la música y al guarapo del indio Domingo. Este tipo de festejos ocurrían con frecuencia entre los habitantes de Popayán y, en general, de toda la Nueva Granada a fines de la colonia en espacios privados o públicos ${ }^{20}$. Sin embargo, no siempre fue así. Este modo de socialización entre gentes de diferentes etnias alrededor de una bebida embriagante solo comenzó a ser posible a partir del siglo XVII cuando, cómo lo ha expuesto Gregorio Saldarriaga, la aparición de chicherías en centros urbanos creó nuevos espacios y formas de consumo impuestas por los españoles ${ }^{21}$. Esto contribuyó a la disminución de la ingesta de chicha como ritual ancestral entre indígenas, quienes, a su vez, adquirieron gradualmente mayor acceso al consumo y producción de otras bebidas tales como el guarapo y el aguardiente a través del intercambio monetizado. Más allá de lo que esto significó para la cultura de las comunidades indígenas, este nuevo marco de consumo estableció y definió las prácticas de consumo durante la colonia.

16 En 1815, el guarapo del indio Domingo no solo fue su fuente de sustento, también fue un instrumento a través del cual se mantuvieron prácticas de socialización y de diversión en un año convulsionado por el comienzo de la restauración en la Nueva Granada. Aunque terminara de forma trágica, como sucedió en este y otros casos, la práctica de reunirse con otros a cenar, bailar y beber, aún en tiempos de guerra, refleja lo importante que fue para la gente del común mantener intacta esa dimensión de la convivencia social que se originaba en el interés de hacer negocios para subsistir. Estos detalles que brotan del expediente judicial ofrecen otra imagen sobre la ingesta de licor por fuera de los campos de guerra, en donde los soldados usualmente bebían para ahuyentar el frío, llenarse de valor con "fuerzas artificiales para entrar en combate" y celebrar victorias ${ }^{22}$. Dentro o fuera de las zonas de batalla, lo cierto es que el consumo de licor especialmente inmoderado representó para las autoridades una amenaza al orden social y/o al desempeño militar, por lo que el gobernador José Solís decretó en un bando de febrero de 1817 que en Popayán quedaban "vedadas las borracheras bajo penas progresivas de multa, cárcel o destierro para los ebrios, los expendedores de licores y todos aquellos que incitaran al consumo" ${ }^{23}$. Ante estos hechos y dado que Ballesteros cometió el crimen estando ebrio, ¿lograría con su carta que el gobernador Solís se compadeciera de él?

\subsection{La diferenciación sociorracial registrada en el caso criminal}

Antes de referirnos a la decisión que finalmente tomaría el gobernador Solís sobre la situación de Ballesteros, es necesario desmenuzar otros detalles encontrados en las declaraciones con el fin de capturar la complejidad social que registra el expediente sobre el transcurrir cotidiano entre la gente del común en Popayán durante la restauración. Como historiadores, Leo Garofalo y Rachel O'Toole advierten que, "necesitamos entender más sobre cómo los trabajadores rurales, los agricultores, los ganaderos, los vendedores y los arrieros se apoderaron de las categorías coloniales de diferencia o se identificaron de acuerdo con estos términos" ${ }^{24}$. En esta dirección apunta la presente sección, en tanto el episodio de violencia ocurrido la noche del 21 de julio de 1815 en Cajibío es un evento privilegiado para comprender las relaciones sociorraciales que enmarcaron la socialización de estas gentes. Es por esto que analizaremos la textura de las relaciones sociales plasmadas en el caso con relación a la diferencia. La lectura meticulosa del registro nos permite indagar sobre las ideas 
relacionadas con el color de piel de las personas y las asociaciones con inferioridad o superioridad social que supuestamente exhibieron los involucrados la noche del suceso y que replicaron en sus declaraciones.

En el periodo colonial, Popayán se caracterizó por ser una sociedad esclavista constituida por una variedad de grupos, incluyendo gente mestiza, comunidades indígenas, blancos pobres, población esclavizada y libre de ascendencia africana y un grupo selecto de criollos y peninsulares que casi siempre pertenecieron a familias poderosas y se ocupaban como mineros, esclavizadores, comerciantes, clérigos y servidores públicos. Ninguna de estas categorías sociorraciales, sin embargo, supuso grupos estrictamente definidos y limitados por parámetros de color, clase, estatus o género. A fines de la colonia, por ejemplo, hubo gente esclavizada con acceso a un tipo de "libertad transitoria" 25 que les permitía, entre otras cosas, mendigar comida lejos de las haciendas donde laboraban o realizar transacciones económicas con otras personas sobre toda clase de insumos. También hubo blancos pobres que, llevados por su ambición de acumular riqueza, accedían a encargarse de minas de oro en lugares inhóspitos donde sus jefes no se atrevían a pasar más de una noche. Incluso mujeres casadas y viudas utilizaron su poder como dueñas de minas y esclavos para imponerse en regiones como la costa Pacífica, desafiando la común caracterización de las mujeres como no aptas para la empresa ${ }^{26}$. El curso de vida de las personas en esta sociedad y la convivencia con otras estuvo entonces mediado por una escala social jerárquica con múltiples categorías que no siempre fue rígida.

La complejidad de estas categorías aparece plasmada en este expediente de diferentes maneras empezando por el calificativo "montañés" con el que el soldado Ballesteros se identificó o lo identificaron las autoridades que tomaron sus declaraciones. El significado de "montañés" parece haber variado de acuerdo con el momento histórico, las circunstancias y la ubicación geográfica ${ }^{27}$. Marta Herrera en una discusión al respecto explicó que en los Andes el calificativo "montañés" asumió un factor racial asociado con el "mestizo" y el "indígena" en algunas áreas y con el "blanco" en otras. Durante el siglo XVIII, en las ciudades de Cali, Caloto y Quilichao, todas dentro de la jurisdicción de Popayán, se utilizó el término con la connotación de "blanco"28. Con base en esto, es muy probable que Ballesteros por haber vivido en dicha jurisdicción y por haberse dedicado a ser jornalero cuando no prestaba servicios al rey, se reconociera a sí mismo y/o lo señalaran como blanco pobre o simplemente "montañés". Una pregunta fascinante que formula Herrera y que parece bastante relevante para esta discusión es “¿qué tan distinto era un [negro/mulato] libre pobre de un blanco pobre?”.

Para nuestro caso, recordemos que la víctima de Ballesteros fue identificada en el expediente judicial como un hombre negro libre. Aunque encontramos pocos detalles sobre lo que en vida fue el negro Tenorio, sabemos por su viuda que juntos compraban guarapo al indio Domingo para revender en la ciudad y que eran pobres. También sabemos que fue disfrutando su gusto por la música y la bebida que encontró su muerte. De acuerdo con la poca información que poseemos, podría decirse que si algo diferenciaba a Ballesteros de Tenorio era el servicio militar y la categoría sociorracial bajo la cual se le identificaba. Tenorio, a diferencia de Ballesteros, no había servido a ningún ejército según la información en el expediente. Esto pese a que hombres negros libres y esclavizados pudieron incorporarse formal o informalmente a los ejércitos revolucionaros y realistas durante las guerras de independencia, algo que no había sido posible durante la colonia. En Popayán, muchas de las familias poderosas de la 
provincia afiliadas al realismo español, forjaron relaciones clientelistas con grupos indígenas, negros esclavizados de las minas de oro del Pacífico y negros libres del Patía para asegurar mayor respaldo a la causa monárquica $\mathrm{y}$, de paso, influenciar o manipular otras esferas de la vida cotidiana de esas personas y de sus familias ${ }^{29}$.

El interés, y más que eso, la necesidad que tuvieron las autoridades que lideraban las campañas militares de mantener como aliados a grupos de personas que consideraban social y racialmente inferiores les obligó a reclutarlos y a afianzar el vínculo a través de la lealtad. Es así como el reclutamiento de negros para las tropas durante la crisis monárquica representó una estrategia militar para los diferentes bandos y al mismo tiempo una apertura de nuevos canales de participación social y de lucha que muchos soldados asumieron de acuerdo a lo que entendían por derecho y libertad ${ }^{30}$. A pesar de que la deserción fue constante, servir a las tropas de cualquiera de los bandos políticos por lo general se asumía con compromiso y soldados de todas las categorías sociorraciales se aseguraban de hacer notorio su servicio entre sus conocidos con el fin de inspirar respeto y sedimentar su reputación en la comunidad ${ }^{31}$. Al atravesar por su peor momento, Ballesteros hizo uso de su historial militar para apelar a las autoridades realistas resaltando su lealtad y continua disposición a servir al rey. En el caso de Tenorio, sin embargo, no se menciona algún pasado militar o afiliación a bando, ni siquiera por su viuda cuando intercedió en el caso ${ }^{32}$.

El factor socio racial fue la otra diferencia entre Ballesteros y Tenorio que sí salió a relucir de forma palpable en el expediente y esta relacionado a los hechos previos al crimen. Según Ballesteros, en su carta al gobernador Solís, fue Tenorio quien lo atacó primero y sin motivo. De haber sido así, ¿qué pudo haber desencadenado tanta furia en Tenorio? ¿Cuáles fueron las circunstancias que antecedieron el hecho? Después de horas de baile y bebida, Ballesteros y Ratona se retiraron de la fiesta para descansar. Aunque Ballesteros era casado, Ratona no era su esposa por lo que los asistentes al festejo se refirieron a ella públicamente como la concubina. El resto de los asistentes continuó con el festejo hasta que una discusión de celos entre Manuela y Tenorio provocó ruidos y llantos que despertaron a Ratona. Ratona se levantó y supuestamente gritó, con base en los ruidos que escuchó, que Tenorio, por ser negro, exhibía un comportamiento público escandaloso. Esto, en otras palabras, insinuó que Tenorio era inherentemente revoltoso por su calidad de hombre negro. Sobre este término, Joanne Rappaport observó que fue calidad y no el concepto moderno de raza el que se privilegió en los procesos de identificación y diferenciación entre las gentes que habitaron el territorio durante la colonia, especialmente en los siglos XVI y XVII.

El concepto de calidad en cierta medida "se superpone a los diversos métodos para distinguir etnicidad, estatus e incluso género, porque se origina, simultáneamente, en atributos visibles e invisibles, algunos de ellos heredados y otros adquiridos en el transcurso de la vida y que son expuestos por el vestuario y arraigados en la geografía"33. Rappaport y Herrera coinciden, entonces, en que en el momento de etiquetar socialmente a otros o así mismos se consideraba la posición geográfica y la condición material visible e invisible de un individuo ${ }^{34}$. Bajo estos parámetros, es interesante ver que inmediatamente después de referirse hacia Tenorio con insultos, Ratona lo confrontó directamente recriminándole que se sintiera con la libertad de pelear y hacer estragos solo porque estaban en la casa de "unos pobres indios" ${ }^{35}$. De esta forma, Ratona señaló la pobreza y la representación de Domingo como indio de zona rural, estableciendo una relación situacional y ubicando a Tenorio en un nivel aún 
más inferior por ser negro y exhibir comportamientos que para ella eran indeseables. Que Ratona se sintiera con la libertad de hacer esas observaciones entre sus conocidos demuestra que entendía la jerarquía del sistema social clasificatorio y sugiere, quizá, que se reconocía así misma en una posición socio racial distinta.

Se puede pensar que las observaciones que hizo Ratona sobre "negros escandalosos" e "indios tristes" eran comunes y persistieron en contextos similares en la zona a través del siglo XIX por las semejanzas que encontramos en, por ejemplo, las memorias del viajero estadounidense Friedrich Hassaurek. Su relato de un festejo al que asistió cuando visitaba una hacienda azucarera en el Valle del Chota, al norte de los Andes, revela observaciones cargadas de caracterizaciones sociorraciales que estereotipan prácticas culturales al mismo tiempo que ubican a las personas de diferentes grupos en relaciones jerárquicas:

En talento y gusto musical, estos negros son infinitamente superiores a los indios. Sus melodías no son tan monótonas ni tan sin vida como las de los aborígenes. Por el contrario, [sus melodías] son variadas y ardientes, y están llenas de un vigor emocionante. Su danza no se rige por el paso lento y medido de los indios, sino que se caracteriza por el arrastre y los trazos salvajes y la gesticulación extravagante tan peculiar del etíope. [Los negros] bailan varias danzas, algunas de las cuales son irresistiblemente cómicas. En esto son de un genio inventivo superior al de los blancos y cholos pobres, que no pueden avanzar más allá de la lenta y monótona [danza llamada] alza que te han visto ${ }^{36}$.

La descripción que hizo Hassaurek sobre las personas negras e indígenas que observó en medio de un festejo en un trapiche se rige por una categorización de inferior a superior en la ejecución de ritmos y movimientos. Aunque Hassaurek publicó sus memorias por lo menos cincuenta años después del periodo que se examina en este artículo, se puede pensar que la prevalencia y la circulación de esas ideas entre gente local y extranjera fue amplia y dominante en esta zona andina. En Popayán, el guarapo y la música unieron a negros, indígenas y mestizos aún cuando la diferenciación social era latente. Tales prácticas de socialización no tienen porque pasar desapercibidas cuando se entiende, por las narrativas convencionales, que durante este período primaba otra clase de diferenciación: los bandos patriotas y realistas ${ }^{37}$.

¿Pero cómo respondió el negro Tenorio a los insultos de Ratona? De acuerdo con las declaraciones, Tenorio se molestó con Ratona porque ella profirió ofensas en su contra públicamente. Humillado, Tenorio le pidió silencio a Ratona y la pateó exigiendo respeto. Ratona declaró que al verse atacada y golpeada por Tenorio despertó a Ballesteros para que la defendiera, y éste, aún medio dormido y ebrio, reaccionó. Sobre este punto, las versiones de los testigos cambian: unos acusan a Ballesteros y otros a Tenorio de haber comenzado la trágica riña. No se considera necesario aquí exponer las discordancias entre las declaraciones para concluir que este tipo de fuentes primarias son poco confiables si el único fin de quien las utiliza es determinar quién fue o no el culpable. Lo verdaderamente valioso es señalar que en la construcción de esas declaraciones para el sistema judicial se detectan discursos y ficciones que utilizaron los involucrados para contar la verdad a su modo y protegerse así mismos detrás de la palabra. Esos discursos y ficciones se basaron en ideas y prejuicios de carácter sociorracial, utilizados como arma, no en los campos de guerra, pero sí en las confrontaciones en el terreno judicial.

De manera que, en Popayán durante la restauración, personas como Ratona, socializaban con gente que consideraban diferente en el día a día, pero no por esto 
abandonaban $\mathrm{u}$ olvidaban la invisible construcción social de la diferencia que demarcaba sus posiciones y experiencias en la vida pública. En un momento de ira o frustración, Ratona interpretó la conducta de sus conocidos con base en su entendimiento de las estructuras sociales jerárquicas que definieron la vida en Popayán aún durante la guerra. Estas estructuras, a su vez, estaban basadas en un imaginario que entrelazaba y ponía en circulación ideas dominantes sobre las características que debía poseer una persona para que fuera merecedora de respeto, honor, y reconocimiento público. Sobre estos temas ya se ha dicho mucho en la historiografía general, sin embargo, en lo concerniente a Popayán, reducir la escala de observación para capturar esos momentos en los que personas del común encarnaron ideas "abstractas" no solamente revela las tensiones de carácter sociorracial que repercutieron en las relaciones interpersonales cotidianas por fuera de las zonas de combate, también humaniza el oficio de reconstruir la historia en tiempos de guerra. Al final, parece que el negro Tenorio se resistió verbal y físicamente a ser encasillado y a recibir insultos por parte de Ratona, pero ¿qué ocurrió entre él y su esposa Manuela para que Ratona se ofendiera y se desencadenaran los eventos trágicos de la noche?

\subsection{Violencia física y conyugal}

"Mulatico Isidro", el joven esclavizado que también asistió al festejo aparece relativamente al margen en las declaraciones recolectadas en el caso, excepto cuando se habla de la situación que dio origen a la pelea por celos entre Manuela y el negro Tenorio. Todo comenzó cuando "mulatico Isidro" sostuvo una conversación casual con Manuela y le preguntó si ella sabía algo sobre el paradero de una mujer mulata llamada Josefa Zúñiga ${ }^{38}$. Al parecer, fue por esta simple pregunta que Manuela y el negro Tenorio comenzaron a discutir. El expediente no revela información sobre quién fue Josefa Zúñiga, pero la evidencia recolectada en el caso indica que ella habría sido concubina de Tenorio y que Manuela recibió un golpe en la cabeza por revelar a su esposo que estaba al tanto de todo y mostrar su inconformidad en público. Todos los testimonios, incluso el de Ratona y la confesión de Ballesteros, coincidieron en que cuando Manuela respondió que Josefa ya no vivía en Popayán, el negro Tenorio se exaltó, gritó que no era cierto, le advirtió a Manuela que no hablara de lo que desconocía y procedió furioso a "descalabrarla" con un ladrillo ${ }^{39}$. Manuela reconoció la actitud y reacción agresiva de Tenorio en su propia declaración, pero, quizá con el fin de humanizar a su esposo, también resaltó que este se mostró "apesarado" inmediatamente después de golpearla e intentó reconfortarla ${ }^{40}$.

El altercado entre Manuela y su esposo no solo dio pie a una serie de ofensas verbales y físicas cambiaron drásticamente el ánimo festivo de la noche. Tenorio agredió a Manuela físicamente por atreverse a hablar, manifestar sus pensamientos y contradecirlo en público. Según el "mulatico Isidro", Tenorio le gritó a Manuela antes de agredirla que "se callase la boca" pero "después del hecho le pesó al difunto el haber descalabrado a su mujer y tiro a consolarla" ${ }^{41}$. Domingo, por su parte, declaró que "tuvo celos la Manuela con el marido hasta que este se enfadó y cogió un ladrillo y la descalabró. Que con esto [ella] quedó callada" ${ }^{42}$. Ratona dijo que, informada por Domingo, Manuela contradijo a Tenorio, afirmando que Josefa se había ido de la ciudad pero que como a su esposo "le dolía [la ausencia de Josefa] volvía por ella, por lo que comenzaron a enredarse por celos hasta que el Tenorio se enfadó" ${ }^{43}$. Según el acusado Ballesteros, Manuela habría dicho a su esposo "que como [Josefa Zúñiga] era su 
concubina [él] tenía razón de saber en donde existía" por lo que "la maltrató hasta romperle la cabeza" ${ }^{44}$. Resulta inquietante que Ballesteros tuviera tanta claridad de un hecho que ocurrió cuando él ya se había retirado de la escena a descansar. Queda entonces la duda de si escuchó el conflicto desde donde dormía o si repitió lo que escuchó decir a los demás porque le podría convenir.

Fuera cual fuera la respuesta, lo cierto es que Manuela salió herida de su discusión con Tenorio. Tal violencia entre la pareja y en presencia de otras personas no parece alarmante en un periodo en el que los conflictos por amistades ilícitas fueron comunes y en el que los esposos tenían la plena libertad de "reprender" a sus esposas sí, en su criterio, ello era necesario. Las amistades ilícitas, así denominadas por las autoridades coloniales en la Nueva Granada, consistían en encuentros sexuales y/o uniones familiares por fuera de la institución del matrimonio, tales como el concubinato, el amancebamiento, el adulterio y el incesto. Fue una práctica bastante común y generalizada entre personas de todo tipo de origen socioeconómico en el territorio. Lo fue, incluso, entre miembros de la elite social, quienes en muchos casos lograron mantener dichas relaciones en secreto y fuera del ojo público para proteger sus reputaciones personales y el honor familiar. Aquellos pertenecientes a las clases bajas no contaron con los mismos recursos para esconder sus amistades ilícitas de la constante supervisión de la Iglesia y de las autoridades legales. Dicha supervisión la realizaban comisarios de barrio quienes eran hombres asignados por un alcalde pedáneo para patrullar las calles de la provincia en busca de comportamientos morales por corregir. Es así como los comisarios de barrio tenían la libertad de inspeccionar casas familiares y sitios públicos donde el comportamiento de la gente levantara sospecha. Fue muy común, por ejemplo, que los comisarios de barrio buscaran y detuvieran parejas en pecado por estar conviviendo por fuera del matrimonio o por ser infieles a sus legítimos esposos ${ }^{45}$.

31 Aunque este expediente se levantó por la muerte del negro Tenorio y no por una acusación de amistad ilícita contra Tenorio y Josefa Zúñiga, el supuesto comportamiento inmoral de Tenorio al tener una concubina causó tensiones entre él y Manuela que tuvieron las repercusiones serias que ya conocemos. Ballesteros intentó en sus declaraciones explotar esta pieza de información para descalificar el carácter moral del negro Tenorio. Y aunque sus intentos no tuvieron mayor repercusión en este caso en particular, hay otros en el archivo en los que, por ejemplo, una acusación por amistad ilícita contra un subteniente del ejército realista dos años antes del inicio de la restauración en Popayán, por poco descarrila y arruina sus planes militares. Para las autoridades realistas en la provincia de Popayán, las amistades ilícitas promovían desorden social y moral, por lo cual era su deber contenerlas a toda costa vigilando moralmente y disciplinando legalmente a hombres y mujeres -principalmente del común- involucrados en esas relaciones. Es por esto que la apertura que brinda este caso judicial para arrojar una luz sobre el tema de las amistades ilícitas es relevante pues aún en medio de una transición marcada por la violencia política y militar esas relaciones continuaron definiendo la vida conyugal, cotidiana y hasta el destino de las personas ${ }^{46}$. Manuela, al parecer muy consciente de lo mal visto que una acusación por concubinato podía verse ante los ojos de la Iglesia y de la ley, utilizó lo que sabía de la relación extramarital entre Ballesteros y Ratona para persuadir a las autoridades de arrestar a Ratona, como veremos a continuación. 


\section{Quejas y dilatación del proceso judicial}

\subsection{Manuela Vega - viuda y vendedora de guarapo- reclama justicia}

32 Los detalles que ofrece el expediente judicial para dimensionar la complejidad de la historia detrás de la muerte del negro Tenorio ya se han desmenuzado, ilustrando una imagen de cotidianidad en una noche de fiesta que terminó en tragedia. Ahora, ¿qué pasó con la administración de justicia en este caso como tal?

Un mes después del crimen, la viuda Manuela presentó una queja escrita ante el gobernador de Popayán, que ese año era de filiación patriota, por el triunfo que tuvieron en la batalla del Río Palo. Manuela utilizó el recurso de la queja -seguramente con la asistencia de un escribano quien redactó y firmó por ella- para exigir justicia por su esposo. La queja hacía hincapié en dos puntos: lamentaba la demora de las autoridades en resolver el caso pues ya había pasado un mes desde la muerte de Tenorio y que el procedimiento parecía estar estancado en la recolección de declaraciones de testigos. Por otro lado, Manuela también expresaba su preocupación sobre la conducta de Ratona. Para Manuela, Ratona había sido cómplice de Ballesteros la noche del crimen no solo porque lo alentó a pelear con Tenorio sino porque también lo animó a huir de la escena del crimen a caballo al enterarse de que Tenorio había amanecido muerto. Por estos motivos, Manuela acusaba a Ratona de cómplice ante las autoridades y se refería a ella repetidamente como concubina para enfatizar su falta moral, considerada pecado y delito, como ya hemos visto.

Ratona fue una de las detenidas por la muerte de Tenorio, pero no enfrentó cargos criminales a pesar de admitir que animó a Ballesteros a escaparse el día después del crimen para evadir a las autoridades. A Manuela le resultaba incomprensible que Ratona hubiera recuperado la libertad pocos días después de su arresto y le molestaba que anduviera paseándose libremente por las calles de la ciudad de Popayán, “insultándome y provocándome cuando me ve, debiendo yo ser la agraviada" ${ }^{47}$. La supuesta altanería de Ratona incomodaba a Manuela no solo porque la quería arrestada, por complicidad en la muerte de su esposo, sino también porque los supuestos insultos y comentarios desmedidos en público teñían aún más su imagen de viuda. Manuela, a diferencia de mujeres viudas con dote para atraer a un nuevo marido, no tenía más que su honra. Para ella, como para muchas otras mujeres pobres, "la muerte del esposo implicaba la pérdida de una figura protectora y paternalista [...] dejándola vulnerable para enfrentar una nueva realidad" ${ }^{48}$. En la Nueva Granada la realidad en el marco de la transición política entre la colonia y la república significó defenderse de los insultos públicos, pues estos ocasionaban deshonra y mala reputación ${ }^{49}$.

Manuela, viuda y pobre, se rehusó a aceptar las ofensas que mancillaban su nombre y reputación, dejando registro de ello en su queja formal al gobernador patriota. Por esto cerró su queja exigiendo a las autoridades que volvieran a arrestar y encarcelar a Ratona por su posible complicidad en el crimen y hasta que todo estuviera resuelto. Seguramente este tipo de exigencias por parte de una viuda no parecieron tan fuera de lugar, pues, en general, las viudas participaron activamente en los estrados judiciales durante toda la colonia. Este expediente criminal refleja, sin embargo, que las autoridades en Popayán hicieron caso omiso a las quejas de maltrato verbal interpuestas por Manuela contra Ratona. Sobre este tema, María Eugenia Albornoz ha 
explicado que la violencia interpersonal de obra y de palabra entre mujeres se entendía en la época colonial como "comportamientos violentos femeninos individuales menospreciados por las autoridades" pues para ellos se trataba de "pleitos menores que no se [debían] atender" ${ }^{\prime 50}$.

Las autoridades ignoraron las acusaciones de la viuda Manuela contra Ratona, pero mostraron suficiente interés en agilizar el proceso contra Ballesteros. Pocos días después de haber recibido la queja de Manuela, las autoridades tomaron la última declaración de testigos que les faltaba e interrogaron por primera vez a Ballesteros en la cárcel. A partir de esto, la maquinaria judicial se activó y el juez encargado asignó fiscal y defensor al caso. El primer defensor nominado rechazó la designación "por hallarse muy ocupado en asuntos de las tropas", excusa que se repite constantemente en las fuentes judiciales del período y que deja ver, aún en su brevedad, lo dificultoso que debió ser enlistar en este tipo de casos a los pocos abogados que vivían en la provincia a consecuencia de la guerra ${ }^{51}$. También se ordenaron dos rondas de ratificaciones de testigos, la posición del fiscal Mariano Ramírez (quien señaló asignar castigo de acuerdo con la Recopilación castellana) y dictamen del asesor legal asignado, don Santiago Pérez de Valencia y Arroyo. Todos estos avances en el caso se produjeron entre 1815 y 1816, año en que fue interrumpido el proceso por la derrota de los patriotas en otra batalla que los obligó a desocupar la ciudad.

Sería erróneo asegurar que fue gracias a la intervención temprana de la viuda Manuela reclamando justicia por la muerte de su esposo que el caso finalmente despegó y las autoridades encargadas comenzaron a hacer su trabajo. Lo que sí podemos decir es que el reconocimiento de su queja y posterior archivo dentro del expediente fue algo significativo cuando la revisión de otros casos judiciales sugiere que esto era un tanto inusual para las mujeres de la época. Manuela hizo uso de los canales legales a su disposición tales como declarar en calidad de testigo y expresar indignación por la dilatación del caso. Hacer esto por voluntad propia o animada por un tercero no cambia que existiera ese espacio de acción en un contexto de guerra para una mujer pobre como ella, aunque al final el resultado no le satisficiera. También podemos decir que la frustración que sintió frente a lo que consideró una lenta administración de justicia en el proceso de determinar y sentenciar castigo en casos judiciales criminales no fue un sentimiento único o aislado. Otras personas vinculadas al caso como el propio acusado y hasta el asesor legal pensaron de igual forma. Tomar las riendas del andamiaje legal fue clave para que el bando victorioso que ocupara la ciudad de Popayán se sintiera realmente con poder. Pero la lenta ejecución de casos por las circunstancias de guerra y las confusiones y desmanes propias de una transición política inestable no mostraba más que desorganización interna y choques ideológicos representados en las acciones para acatar, interpretar y/o ejecutar la ley tal y como se muestra en la siguiente sección.

\section{2. Ballesteros pide compasión y el asesor celeridad}

En una queja que dirigió al juez encargado del caso entre marzo y abril de 1816, Ballesteros expresó frustración porque a pesar del tiempo que llevaba en prisión, su caso apenas estaba en sus "primeros principios" y anhelaba que "algún día lograra su conclusión" ${ }^{2}$. Su frustración también se debía al deterioro de su salud a causa de los grilletes que llevaba en los pies, por lo cual en varias ocasiones pidió reconocimiento médico. Ballesteros nunca imaginó que su estadía en prisión sería larga. Tal como lo 
manifestó en su carta al gobernador Solís en 1818, cuando fue arrestado por matar al negro Tenorio pensó, equivocadamente, que no tardaría mucho en quedar libre pues "veía que [su] desgracia no había sido un hecho pensado"53. Pero al cabo de casi doce meses seguía recluido y sin conocimiento alguno sobre su situación jurídica.

Ballesteros no fue el único que se quejó por la demora de las autoridades patriotas en procesar su caso. Alrededor de dos meses antes de su queja, el propio asesor legal del caso Arroyo manifestó su indignación por la dilatación del proceso. Arroyo, lamentó que, aunque "en ningunas otras causas debe procederse con más celo y actividad que en las criminales, la experiencia acredita todos los días el abandono con que se miran" ${ }^{54}$. Y es que la experiencia de Arroyo era extensa y reconocida, pues como abogado y miembro de una familia adinerada y patriota de Popayán había servido como asesor legal y juez en cientos de casos civiles y judiciales, incluso cuando el bando político al mando era el realista. Sus años de experiencia le permitían observar, por ende, que el caso sobre "la muerte del negro Tenorio debía de estar ya concluid[o] hace tiempo" pero que se había entorpecido por la falta de acción de las autoridades encargadas, quienes, a su vez, incurrieron en una serie de "vicios" en el proceso que tenían que ser corregidos $^{55}$.

En su afán por establecer orden y legitimidad en el proceso, Arroyo sugirió que era imprescindible que le llegaran notificaciones al reo sobre el estado de su caso; que peritos maestros en cerrajería examinaran el arma con que se dio muerte a Tenorio; y que un cirujano reconociera el arma y diera cuenta de su relación con las heridas mortales ${ }^{56}$. El maestro y el cirujano coincidieron en sus reportes al asesor en que el arma utilizada era "prohibida y de contundente magnitud para matar" ${ }^{57}$. Arroyo también recomendó que se hicieran nuevas preguntas a todos los testigos con relación a las heridas que sufrió Tenorio y que verificaran la fecha en que ocurrió la tragedia ${ }^{58}$. En otras palabras, Arroyo intentó agilizar el proceso, al mismo tiempo en que enseñaba a las autoridades encargadas los pasos procesales que nunca debían saltarse. Esto siempre caracterizó a Arroyo como abogado, pues se empeñaba en que todos los procedimientos legales a su cargo se llevaran al pie de la letra, como ordenaba la ley. Según él, no ser arbitrario en la interpretación de la ley y la práctica judicial eran cualidades que lo distinguían de los realistas.

Era tal la convicción de Arroyo en frenar cualquier desorden, que no dudó en regañar y multar al escribano del caso, Don Manuel Velasco, por tardar poco más de un mes en recolectar las certificaciones y ratificaciones que el mismo Arroyo había ordenado en su primera asesoría. Entre esas certificaciones estaba la del médico cirujano Wallis, quien tras examinar a Ballesteros en prisión determinó que el reo padecía de hidropesía como consecuencia de los grilletes en sus pies. Arroyo permitió entonces que le quitaran los grilletes y ordenó que el alcalde de prisión le aplicara "los medicamentos necesarios para su curación" 59 . Una vez le quitaron los grilletes que llevó en sus pies por seis meses, Ballesteros recuperó movilidad en sus piernas, que bien aprovechó meses después, cuando huyó de prisión con todos los presos al enterarse del triunfo de las tropas realistas en la batalla de La Cuchilla de El Tambo en junio de $1816^{60}$. Esta victoria liderada por Juan Sámano y las guerrillas patíanas al mando del negro Simón Muñoz, permitió a las fuerzas realistas recuperar el control sobre la provincia de Popayán para ponerla nuevamente a disposición del rey de España y así concretar el principal objetivo del ejército Pacificador: restaurar el poder y dominio de la corona española sobre el territorio neogranadino. 


\section{Fuga, recaptura e indulto}

julio de $1817^{63}$. Un año más tarde, Ballesteros intentaba ampararse en él resaltando que a sus más de sesenta años vivía y trabajaba "tranquilamente en [su] yunga". Fue necesario para Ballesteros destacar que aún trabajaba a pesar de su avanzada edad para que no se le considerara vago, pues entre las condiciones para gozar del indulto estaba precisamente no ser uno de ellos. Ballesteros también se aseguró de describir su anterior servicio al rey como chasqui o mensajero y el deterioro de su salud a causa de la hidropesía que desarrolló la primera vez que estuvo preso bajo autoridad patriota. Para la satisfacción de Ballesteros, su carta fue bien recibida y las autoridades realistas de Popayán, el gobernador Solís y el asesor general Antonio Carvajal y Tenorio, estuvieron de acuerdo en otorgarle el indulto con una única condición: estar dispuesto a trabajar como chasqui para el rey si así fuese necesario y a no regresar por las tierras donde cometió el crimen ${ }^{64}$. hombre común como Lucas Ballesteros establecer un registro de servicio al rey para recibir amparo y que su caso judicial fuera finalmente cerrado. Su narrativa concuerda con las acciones de las fuerzas realistas que, por ejemplo, en 1818 hicieron fuertes campañas para reclutar a cuantos hombres pudiesen sin importar que fueran "chisperos, vagos y mal entretenidos", puesto que era preferible ocuparlos en cualquier actividad que beneficiara al rey. Para los realistas, tener suficientes hombres a disposición era entonces fundamental para encarar una posible agresión y contraataque por parte del ejército patriota liderado por Simón Bolívar como eventualmente ocurrió en 1819. En este contexto, es claro que el crimen y el castigo de Ballesteros pasaron a un segundo plano y se dio prioridad al servicio que podría prestarle al rey.

Por otro lado, el hecho de que Ballesteros haya pasado tiempo en prisión durante el año de ocupación patriota en Popayán no necesariamente significa que los patriotas se inclinaran más por hacer justicia. Es muy probable que conociendo las tendencias 
políticas de Ballesteros este haya permanecido encerrado no solo como castigo, sino también como estrategia para disminuir o limitar la disponibilidad de hombres que pudieran contribuir a la causa realista. De haber sido así, la búsqueda de justicia por parte de la viuda Manuela como la de otras mujeres en este periodo estuvo siempre a la merced del bando político al mando y de los intereses y prioridades que aquellos tuvieran para asegurar orden y su permanencia en el poder.

\section{Conclusiones}

Este articulo resalta los múltiples ángulos que marcaron la vida cotidiana de la gente del común que vivió en Popayán durante la restauración monárquica en la Nueva Granada a través de la lectura crítica de un sustancioso expediente criminal con el fin de demostrar el potencial que tienen este tipo de fuentes primarias para expandir nuestro entendimiento sobre la dimensión sociolegal de ese periodo histórico. Al ser analizados, los detalles sobre la cotidianidad que brotan del expediente criminal contra Lucas Ballesteros y que fueron corroborados por más de un involucrado abren ventanas para entender lo que acontecía lejos de los campos de batalla, en los espacios íntimos de socialización entre gentes de diferentes grupos sociorraciales que vivían y laboraban en Popayán. El trabajo, la comida, la música y el baile confluyeron para crear espacios de diversión y de camaradería en medio de un periodo dentro de las guerras de independencia que ha sido catalogado en la historiografía como incesantemente violento y sangriento. Los contrastes entre los episodios que enmarcaron la vida diaria de los habitantes de Popayán y las metanarrativas sobre las disputas políticas y militares del periodo merecen ser examinados con el objetivo de complejizar y dinamizar la reconstrucción de la historia y, de paso, ganar un mayor entendimiento sobre los factores políticos que tiñeron la administración de justicia en ese tiempo.

La riqueza documental del expediente examinado en este artículo contiene la agitada narrativa de vida de Ballesteros, quien al demostrar un historial de servicio al rey de España durante en las guerras, logró que cerraran el caso criminal en su contra por homicidio y recibió el indulto que le permitiría seguir gozando de su libertad en Popayán a sus más de sesenta años. Sobre el indulto, es indudable que ello finalmente jugó un rol fundamental en la conclusión del caso y sugiere, como ya han advertido otros historiadores, que hacen falta más estudios que den cuenta sobre cómo las peticiones de indulto moldearon la vida y las relaciones durante las guerras de independencia ${ }^{65}$. Es por esto que la consideración y estudio crítico de estas fuentes puede ser útil para comenzar a llenar ese y otros vacíos $\mathrm{y}$, al mismo tiempo, para apreciar y analizar las vicisitudes que marcaron la vida cotidiana de los acusados, afectados y testigos que vivieron en una época turbia y de caótica transición sociopolítica. En otras palabras, la lectura crítica y profunda de expedientes judiciales, que en Popayán están muy bien conservados, puede no solo ofrecer al historiador herramientas para ahondar en la reconstrucción de la vida social, cultural y legal durante las guerras de independencia. También puede arrojar luz, especialmente cuando hay cruce de fuentes, sobre actores históricos olvidados pero muy relevantes para dimensionar las complejidades del periodo y del sistema legal.

49 La viuda Manuela Vega, por ejemplo, aparece activamente a través de todo el expediente denunciando, testificando, declarando ante las autoridades legales y presionando para que se hiciera justicia. Esa justicia no era solamente para que el 
homicidio de su esposo no quedara impune, también lo era para sí misma como viuda deshonrada. Deshonrada porque quedar sin esposo o figura masculina en casa y recibir ofensas públicas (de parte de alias Ratona, por ejemplo) impactaba negativamente su grado de honorabilidad ante la sociedad payanesa en ese tiempo. La honra fue una característica con enorme peso para la gente de Popayán tal como lo fue en todo Hispanoamérica. $Y$ aunque en este tiempo el sistema de administración judicial en Popayán casi nunca le dio la razón a la mayoría de las mujeres que demandaban a hombres e incluso a otras mujeres para recuperar su honra, es claro que el sistema sí proveyó mecanismos para que quienes se sintieran agraviadas expresaran sus preocupaciones, exigencias y temores a través de declaraciones legales cuyos registros quedarían para la posteridad ${ }^{66}$. De alguna manera la utilización de dichos mecanismos fue, en sí, lo único que tuvieron las mujeres como Manuela para vindicar su honra públicamente o, por lo menos, para intentarlo.

\section{Fuentes}

\section{Fuentes inéditas}

50 ACC, Archivo Central del Cauca, Popayán, Colombia

Fondo Independencia Sala Judicial (J) 1, Anaquel Criminal 3, Signatura 5193.

\section{Fuentes publicadas}

51 Espinosa, José María, Memorias de un abanderado, Imprenta de El Tradicionista, Bogotá, 1876.

52 Hassaurek, Friedrick, Four Years Among Spanish Americans, Hurd and Houghton, New York, 1868.

53 Restrepo, José Manuel, Historia de la revolución de la República de Colombia en la América meridional, Tomo 2, Imprenta de José Jacquin, Besanzon, 1858.

\section{Periódicos}

Gaceta de Madrid (Madrid), n³0, 11 de marzo de 1817.

\section{BIBLIOGRAFÍA}

Albornoz Vásquez, María Eugenia, "La Injuria de Palabra en Santiago de Chile, 1672-1822”, Nuevo Mundo Mundos Nuevos [En Línea], París, febrero 7 2005, Párrafo 15. Disponible en: http:// nuevomundo.revues.org/240 [Fecha de consulta: 25 de octubre de 2020]

Barragán, Yesenia, “Gendering Mastery: Female Slaveholders in the Colombian Pacific Lowlands”, Slavery \& Abolition, London, vol. 39, n¹, 2017, pp. 1-26. 
Blanchard, Peter, "The Language of Liberation: Slave Voices in the Wars of Independence", Hispanic American Historical Review, Durham, NC, vol. 82, n³, 2002, pp. 499-523.

Boyer, Richard, "Negotiating Calidad: The Everyday Struggle for Status in Mexico", Historical Archaeology, vol. 31, no. 1, 1997, pp. 64-73.

Chaves, María Eugenia, "La pregunta y el indicio. A propósito del trabajo sobre fuentes judiciales casos particulares en la investigación histórica sobre los sectores populares", en García, Óscar Almario (ed.), Las fuentes en las reflexiones sobre el pasado: usos y contextos en la investigación histórica en Colombia, Universidad Nacional de Colombia, Medellín, 2014, pp. 143-158.

Chaparro Silva, Alexander, "Fernando VII, el neogranadino. Publicidad monárquica y opinión pública en el Nuevo Reino de Granada durante la restauración absolutista, 1816-1819”, Fronteras de la Historia, Bogotá, vol. 19, n², 2014, pp. 70-95.

Cruz de Amenábar, Isabel, “Tiempos fabulosos y mito de origen: festividades de estado en Chile entre la colonia y la república”, en O’Phelan, Scarlett (ed.), Familia y vida cotidiana en América Latina, siglos XVIII-XX, Institut Français d'études Andines, Lima, 2015. Disponible en: http:// books.openedition.org/ifea/4462 [Fecha de consulta: 25 de octubre de 2020]

Cuño Bonito, Justo, El retorno del Rey: El restablecimiento del régimen colonial en Cartagena de Indias, Universidad Jaume I, Castellón de la Plana, 2008.

Dueñas, Guiomar, “Adulterios, amancebamientos, divorcios y abandono: La fluidez de la vida familiar santafereña, 1750-1810”, Anuario Colombiano de Historia Social y de La Cultura, Bogotá, No. 23, 1996, pp. 33-48.

Echeverri, Marcela, "Los derechos de indios y esclavos realistas y la transformación política en Popayán, Nueva Granada (1808-1820)”, Revista de Indias, Madrid, vol. LXIX, n²46, 2009, pp. 45-72.

Garofalo, Leo J. \& O’Toole, Rachel, “Introduction: Constructing Difference in Colonial Latin America", Journal of Colonialism and Colonial History, Baltimore, vol. 7, n¹, 2006.

Gutiérrez Ardila, Daniel, La restauración en la Nueva Granada, Universidad Externado, Bogotá, 2016.

Herrera Ángel, Marta, Ordenar para controlar: Ordenamiento espacial y control politico en las llanuras del Caribe y en los Andes centrales neogranadinos, siglo XVIII, La Carreta Editores, Medellín, 2007.

Herrera Ángel, Marta, Popayán: La unidad de lo diverso. Territorio, población y doblamiento en la Provincia de Popayán, siglo XVIII, Universidad de los Andes, Bogotá, 2009.

Jiménez Meneses, Orián, El Chocó: el paraíso del demonio: Novita, Citará, y el Baudó, siglo XVIII, Universidad de Antioquia, Medellín, 2004.

Lux, Martha, Las mujeres de Cartagena de Indias en el siglo XVII: Lo que hacían, les hacían y no hacían, y las curas que les prescribían, Universidad de los Andes, Bogotá, 2006, pp. 25-27.

McCaa, Robert, "Calidad, Clase, and Marriage in Colonial Mexico: The Case of Parral, 1788-90", The Hispanic American Historical Review, vol. 64, n³, 1984, pp. 477-501.

McCaa, Robert, "La viuda viva del México borbónico: Sus voces, variedades y vejaciones," en Gonzalo Aizpuru, Pilar (ed.), Familias novohispanas: siglos XVI al XIX, El Colegio de México, México, 1991, pp. 299-324.

McKinley, Michelle, Fractional Freedoms: Slavery, Intimacy, and Legal Mobilization in Colonial Lima, 1600-1700, Cambridge, Cambridge University Press, 2016.

Melo Flores, Jairo Antonio, "El indulto en el proceso de Independencia de la Nueva Granada, 1808-1821", Revista Historia y Justicia, Santiago de Chile, nº, 2016, pp. 228-257. 
Patiño Millán, Beatriz, "Las mujeres y el crimen en la época colonial. El caso de la ciudad de Antioquia”, en Rodríguez, Pablo (ed.), Las mujeres en la historia de Colombia, Editorial Norma, Bogotá, 1995, pp. 77-119.

Pérez Hernández, María Teresa, "Prácticas y representaciones en torno a la familia, el género y la raza. Popayán en 1807”, Convergencia, Toluca, n³7, 2005, pp. 207-245.

Pita Pico, Roger, "La función política de las celebraciones públicas durante el proceso de Independencia de Colombia: en la búsqueda de la legitimidad y la lealtad", Historia y Sociedad, Medellín, n²3, 2012, pp. 175-205.

Pita Pico, Roger, "El consumo de bebidas embriagantes durante el proceso de Independencia de Colombia: aliento, festejo y conspiración”, Historia y Memoria, Tunja, n, 2013, pp. 227-268.

Pita Pico, Roger "Los esclavos y las juntas de secuestros en los procesos de independencia de la Nueva Granada: entre la incertidumbre y la represión política," Anuario de Estudios Bolivarianos, Caracas, $n^{\circ} 19,2012-2013$, pp. 135-173.

Premo, Bianca, The Enlightenment on Trial: Ordinary Litigants and Colonialism in the Spanish Empire, Oxford University Press, New York, 2017.

Rabinovich, Alejandro, Ser soldado en las guerras de Independencia: La experiencia cotidiana de la tropa en el Río de la Plata, 1810-1824, Sudamericana, Buenos Aires, 2013.

Ramírez, María Imelda, Las mujeres y la sociedad colonial de Santa Fe de Bogotá, 1750-1810, Instituto Colombiano de Antropología e Historia, Bogotá, 2000.

Ramírez Bacca, Renzo y Ospina Echeverri, Marta, Cabildo, política y sociedad, 1810-1821. El caso de la provincia de Antioquia, Universidad Nacional de Colombia, Bogotá, 2011.

Rappaport, Joanne, The Disappearing Mestizo: Configuring Difference in the Colonial New Kingdom of Granada, Duke University Press, Durham, 2014.

Rodríguez, Pablo, Sentimientos y vida familiar en el Nuevo Reino de Granada, siglo XVIII, Editorial Ariel, Bogotá, 1997.

Rodríguez, Pablo, "Las hojas del otoño: ancianos y viudos del siglo XVIII neogranadino", Historia Crítica, Bogotá, n¹1, 1995, pp. 53-62.

Saldarriaga, Gregorio, Alimentación e identidades en el Nuevo Reino de Granada - Siglos XVI y XVII, Ministerio de Cultura de Colombia, Bogotá, 2012.

Salinas, René, "Las otras mujeres: madres solteras, abandonadas y viudas en el chile tradicional (siglos XVIII-XIX)", en Fermandois, Joaquín \& Stuven, Ana María, Historia de las mujeres en Chile, Tomo 1, Taurus, Santiago de Chile, 2011, pp. 159-212.

Schechter, John M. y Haefer, J. Richard, “Alfandoque”, Grove Music Online, 2014. Disponible en: https://www.oxfordmusiconline.com/grovemusic/view/10.1093/gmo/9781561592630.001.0001/ omo-9781561592630-e-4002261235 [Fecha de consulta: 25 de octubre de 2020]

Tovar Pinzón, Hermes, “Guerras de opinión y represión en Colombia durante la independencia (1810-1820)", Anuario Colombiano de Historia Social y de la Cultura, Bogotá, n¹1, 1983, pp. 187-232.

Uribe-Urán, Víctor, Honorable Lives: Lawyers, Family, and Politics in Colombia, 1780-1850, University of Pittsburgh Press, Pittsburgh, 2000.

Uribe-Urán, Víctor, “The Lawyers and New Granada's Late Colonial State”, Journal of Latin American Studies, vol. 27, n³, 1995, pp. 517-549. 
Villegas del Castillo, Catalina, Del hogar a los juzgados: Reclamos en el tránsito de la Colonia a la República, 1800-1850, Universidad de los Andes, Bogotá, 2006.

\section{NOTAS}

1. Espinosa, José María, Memorias de un abanderado, Imprenta de El Tradicionista, Bogotá, 1876, pp. 119-120.

2. Restrepo, José Manuel, Historia de la revolución de la República de Colombia. Imprenta de David, Paris, 1827, p. 85.

3. Restrepo, José Manuel, Historia de la revolución de la república de Colombia en la América meridional, Tomo 2, Besanzon, Imprenta de José Joaquín, 1858; Díaz Díaz, Oswaldo, La reconquista española, Academia Colombiana de Historia, Bogotá, 1964; Friede, Juan, La otra verdad: la independencia americana vista por los españoles, Carlos Valencia Editores, Bogotá, 1979; Earl, Rebecca, España y la independencia de Colombia, 1810-1825, Universidad de los Andes, Bogotá, 2014; Gutiérrez Ardila, Daniel, La restauración en la Nueva Granada, Universidad Externado de Colombia, Bogotá, 2016.

4. Gutiérrez, D., La restauración, Op. Cit., p. 279.

5. De acuerdo a la información que registra el censo de 1807, solo en la ciudad de Popayán vivían 2787 hombres y 4277 mujeres de todas las edades. Los hombres aparecen divididos entre las siguientes categorías: 478 blancos, 1260 mestizos, 115 indios, 473 mulatos libres, 33 negros libres, y 428 negros mulatos esclavos. Las mujeres, por su parte, aparecen así: 530 blancas, 1745 mestizas, 239 indias, 745 mulatas libres, 87 negras libres, y 931 negras y mulatas esclavas. Pérez Hernández, María Teresa, "Prácticas y representaciones en torno a la familia, el género y la raza. Popayán en 1807”, Convergencia, Toluca, n³7, 2005, p. 223.

6. Patiño Millán, Beatriz, Criminalidad, ley penal y estructura social en la Provincia de Antioquia, 1750-1820, Universidad del Rosario, Bogotá, 2013.

7. Patiño Millán, B., Criminalidad, Op. Cit., p. XXXIII.

8. Pablo Rodríguez lideró la historia social en Colombia al escribir sobre la vida cotidiana durante la colonia en diferentes ciudades de la Nueva Granada. Sus trabajos han examinado relaciones interpersonales y diversas formas de vida romántica, afectuosa y conflictiva. Ver, por ejemplo: Seducción, amancebamiento y abandono en la colonia, Fundación Simón y Lola Guberek, Bogotá, 1991; Sentimientos y vida familiar en el Nuevo Reino de Granada, siglo XVIII, Editorial Ariel, Bogotá, 1997.

9. Dueñas, Guiomar, Los hijos del pecado, Universidad Nacional de Colombia, Bogotá, 1997; Jurado Jurado, Juan Carlos, Vagos, pobres, mendigos: Contribución a la Historia Social colombiana, 1750-1850, Medellín, Carreta, 2004; López Jerez, Mabel Paola, Las conyugicidas de la Nueva Granada. Transgresión de un viejo ideal de mujer (1780-1830), Editorial Universidad Javeriana, Bogotá, 2006; Villegas del Castillo, Catalina, Del hogar a los juzgados: Reclamos en el tránsito de la Colonia a la República, 1800-1850, Universidad de los Andes, Bogotá, 2006; Tovar Pinzón, Hermes, La batalla de los sentidos. Infidelidad, adulterio y concubinato a fines de la colonia, Universidad de los Andes, Bogotá, 2012; Uribe-Urán, Víctor, Fatal Love: Spousal Killers, Law, and Punishment in the late Colonial Spanish Atlantic, Stanford University Press, Palo Alto, 2015; Pérez Hernández, M., "Prácticas y representaciones", Op. Cit.

10. Villegas del Castillo, C., Del hogar, Op. Cit., p. 19.

11. Villegas del Castillo, C., Del hogar, Op. Cit., p. 18. Sobre los juicios políticos que señala la autora, ver: Tovar Pinzón, Hermes, “Guerras de opinión y represión en Colombia durante la independencia (1810-1820)”, Anuario Colombiano de Historia Social y de la Cultura, Bogotá, n¹1, 1983, p. 217.

12. La microhistoria ha sido un método empleado por historiadores enfocados en la reconstrucción de narrativas que parten de un indicio o un detalle que permite rastrear el movimiento de actores históricos en documentos y contextos e interrogar la relación entre los 
sucesos y dinámicas que ocurren en diferentes escalas de observación. Sobre el método ver: Chaves, María Eugenia, "La pregunta y el indicio. A propósito del trabajo sobre fuentes judiciales y casos particulares en la investigación histórica sobre los sectores subalternos", en Almario García, Óscar (ed.), Las fuentes en las reflexiones sobre el pasado: usos y contextos en la investigación histórica en Colombia, Universidad Nacional de Colombia, Medellín, 2014; Hernández Ciro, Eulalia, "Microhistoria italiana, antropología y archivos judiciales", Historia y Sociedad, Medellín, n³0, 2016; Putnam, Lara, "To Study the Fragments/Whole: Microhistory and the Atlantic World", Journal of Social History, Virginia, vol. 39, n³, 2006. Algunos trabajos que emplean este método son: Cardona Zambrano, Camilo Alexander, Luisa de Venero, una encomendera en Santafé: Microhistoria de las mujeres encomenderas en el Nuevo Reino de Granada, siglo XVI, Editorial Universidad del Rosario, Bogotá, 2019; Perera Díaz, Aisnara y Meriño Fuentes, María de los Ángeles, Esclavitud, familia y parroquia en Cuba: Otra mirada desde la microhistoria, Oriental Ediciones, Santiago de Cuba, 2008; Pérez Morales, Edgardo, Itineraries of Freedom. Revolutionary Travels and Slave Emancipation in Colombia and the Greater Caribbean, 1789-1830, Tesis de doctorado en Historia, University of Michigan, Ann Arbor, Estados Unidos, 2013; Scott, Rebecca, "Reclaiming Gregoria's Mule: The Meanings of Freedom in the Arimao and Caunao Valleys, Cienfuegos, Cuba, 1880-1899", Past and Present, Oxford, n¹70, 2001, p. 181-216; Scott, Rebecca, Freedom Papers: An Atlantic Odyssey in the Age of Emancipation, Harvard University Press, Cambridge, 2012.

13. Archivo Central del Cauca (ACC), Popayán, Colombia, Independencia, Sala Judicial (J) 1, Anaquel Criminal (Cr) 3, Signatura (Sig.) 5193, Foja (f) 36r.

14. ACC, Popayán, Colombia, Independencia, J 1, Cr 3, Sig. 5193, f. $36 \mathrm{v}$.

15. En Colombia, el guarapo es una bebida alcohólica fermentada hecha a base de maíz o de caña de azúcar. En este caso, el guarapo era de maíz.

16. ACC, Popayán, Colombia, Independencia, J 1, Cr 3, Sig. 5193, f. $5 \mathrm{v}$.

17. En su trabajo sobre la transformación de las fiestas cívicas en Chile entre la colonia y la república, la historiadora Isabel Cruz de Amenábar afirma que "el concepto de fiesta ofrece una apertura a la espontaneidad y a la divergencia como manifestaciones de la libertad". En esta sección empleo dicha definición, pues la festividad popular espontánea caracterizó, además de los involucrados en este caso judicial, a muchos habitantes de Popayán y de la Nueva Granada durante la transición de colonia a república independiente. Cruz de Amenábar, Isabel, "Tiempos fabulosos y mito de origen: festividades de estado en Chile entre la colonia y la república", en O'Phelan, Scarlett (ed.), Familia y vida cotidiana en América Latina, siglos XVIII-XX, Institut Français d'études Andines, Lima, 2015 http://books.openedition.org/ifea/4462.

18. El alfandoque es un instrumento idiófono en forma de tubo de caña lleno de semillas duras que producen sonido cuando vibran al sacudirse horizontal o verticalmente. Este instrumento apareció en la región andina colombiana y la costa ecuatoriana a principios del siglo XIX. El alfandoque ha sido históricamente relacionado con las comunidades negras, que lo usaron para crear ritmos y amenizar danzas comunales. Sobre este último punto, el viajero Friedrich Hassaurek describió en sus memorias el rol cultural de este instrumento entre las comunidades negras e indígenas que visitó en Imbabura, región al norte de Ecuador caracterizada por la producción de azúcar, a mediados del siglo XIX. Según Hassaurek, en los festejos que presenció, todas las voces, cantos, aplausos, bailes y exclamaciones de regocijo giraban en torno al "ruido" del alfandoque. Esto apunta a la importancia que tuvieron los instrumentos musicales en construir espacios de socialización y diversión para las personas del común. La presencia del alfandoque en el festejo en la casa de Domingo no solo establece una conexión cultural con la comunidad de ascendencia africana, también denota su convivencia con otras expresiones musicales y culturales representadas por la guitarra y el zumbo. Hassaurek, Friedrick, Four Years among Spanish Americans, Hurd and Houghton, New York, 1868, p. 344.

19. El zumbo es un instrumento musical, también conocido como cencerro, ya que tiene forma de campana y suele atarse al pescuezo de reses y otros animales. 
20. Sobre festejos públicos durante la época independentista ver: Pita Pico, Roger, "La función política de las celebraciones públicas durante el proceso de Independencia de Colombia: en la búsqueda de la legitimidad y la lealtad", Historia y Sociedad, Medellín, n²3, 2012. Alexander Chaparro Silva sostiene que durante la Restauración las autoridades realistas celebraron fiestas y ceremonias de fidelidad con el propósito de generar entusiasmo por la causa fernandina. Con este objetivo, las fiestas oficiales representaron un vehículo para la "publicidad del poderío monárquico". Chaparro Silva, Alexander, "Fernando VII, el neogranadino. Publicidad monárquica y opinión pública en el Nuevo Reino de Granada durante la restauración absolutista, 1816-1819”, Fronteras de la Historia, Bogotá, vol. 19, n², 2014, p. 79.

21. Saldarriaga, Gregorio, Alimentación e identidades en el Nuevo Reino de Granada - Siglos XVI y XVII, Ministerio de Cultura de Colombia, Bogotá, 2012, p. 133.

22. Pita Pico, Roger, "El consumo de bebidas embriagantes durante el proceso de Independencia de Colombia: aliento, festejo y conspiración”, Historia y Memoria, Tunja, n7, 2013, p. 239.

23. Pita Pico, R., "El consumo", Op. Cit., p. 233.

24. Garofalo, Leo, y O’Toole, Rachel, “Introduction: Constructing Difference in Colonial Latin America",

Journal of Colonialism and Colonial History, Baltimore, MD, vol.7, n¹, 2006, doi:10.1353/cch. 2006.0027.

25. El historiador Orián Jiménez ha acuñado el término "libertad transitoria" para explicar la movilidad espacial que disfrutaban algunos esclavos de los distritos mineros del Pacífico cuando sus capataces los mandaban a cazar o a buscar nuevos yacimientos de oro. Jiménez Meneses, Orián. El Chocó: el paraíso del demonio: Novita, Citará, y el Baudó, siglo XVIII, Universidad de Antioquia, Medellín, 2004, p. 70

26. Barragán, Yesenia, "Gendering Mastery: Female Slaveholders in the Colombian Pacific Lowlands", Slavery \& Abolition, London, vol.39, n¹, 2017, p. 1-26.

27. Herrera Ángel, Marta, Popayán: La unidad de lo diverso. Territorio, población y doblamiento en la Provincia de Popayán, siglo XVIII, Universidad de los Andes, Bogotá, 2009, p. 89-94.

28. Herrera Ángel, M., Popayán, Op. Cit., p. 92.

29. Véase: Prado Arellano, Luis Ervin, "El jefe natural: poder y autoridad en el Valle del Patía, 1810-1850", Historia y Sociedad, Medellín, n²3, 2012, p. 243-265; Echeverri, Marcela, Indian and Slave Royalists in the Age of Revolution: Reform, Revolution, and Royalism in the Northern Andes, 1780-1825, Cambridge University Press, New York, 2016; Prado Arellano, Luis Ervin, "Redes, movilización y bases de autoridad en el Valle del Patía, 1820-1851", Historia Caribe, Barranquilla, vol.8, n²2, 2013, p. 75-103.

30. Echeverri, Marcela, "Los derechos de indios y esclavos realistas y la transformación política en Popayán, Nueva Granada (1808-1820)", Revista de Indias, Madrid, vol. LXIX, n²46, 2009, p. 47. Para un estudio sobre el poder del lenguaje entre esclavizados en toda la región ver: Blanchard, Peter, "The Language of Liberation: Slave Voices in the Wars of Independence", Hispanic American Historical Review, Durham, NC, vol. 82, n³, 2002, p. 500.

31. Refiriéndose a los soldados revolucionarios en el Río de la Plata, Alejandro Rabinovich dice que "servir en el ejército era la primera y principal manera de manifestar patriotismo". Eso sumado con vestir un uniforme prestigioso, viajar a tierras lejanas y celebrar victorias ofrecían oportunidades de avance social impensables para muchos. Rabinovich, Alejandro, Ser soldado en las guerras de Independencia: La experiencia cotidiana de la tropa en el Río de la Plata, 1810-1824, Sudamericana, Buenos Aires, 2013, versión digital Kindle: L 216.

32. La ausencia de tal información en el expediente no quiere decir que no exista. El cruce de fuentes se hace necesario para investigar, en lo posible, el rastro que pudieron haber dejado actores históricos en otro tipo de documentación y que permita expandir sobre sus vidas o acciones. 
33. Rappaport, Joanne, The Disappearing Mestizo: Configuring Difference in the Colonial New Kingdom of Granada, Duke University Press, Durham, NC, 2014, p. 41.

34. Para investigaciones relevantes sobre la complejidad y el significado de conceptos como calidad, raza y castas en el ordenamiento del mundo colonial véase: Martínez, María Elena, Genealogical Fictions: Limpieza de Sangre, Religion, and Gender in Colonial Mexico, Stanford University Press, Palo Alto, 2011; Herrera Ángel, Marta, Ordenar para controlar: ordenamiento espacial y control político en las llanuras del Caribe y en los Andes centrales Neogranadinos, siglo XVIII, La Carreta Editores/CESO Uniandes, Medellín, 2007; Rappaport, Joanne, The Disappearing Mestizo, Op. Cit.; McCaa, Robert, "Calidad, Clase, and Marriage in Colonial Mexico: The Case of Parral, 1788-90", Hispanic American Historical Review, Durham, NC, vol. 64, n³, 1984, p. 477-501; Boyer, Richard, "Negotiating Calidad: The Everyday Struggle for Status in Mexico", Historical Archaeology, vol. 31, $\mathrm{n}^{\circ} 1,1997$, p. 64-73.

35. ACC, Popayán, Colombia, Independencia, J 1, Cr 3, Sig. 5193, f. 6r, 11r.

36. Hassaurek, F. Four Years, Op. Cit., p. 344-345. Mi énfasis. En el texto original en inglés Hassaurek utiliza la palabra "rabble" para referirse a los blancos y cholos pobres. En la lengua inglesa, dicha palabra se emplea despectivamente para referirse a gente que se percibe socialmente inferior a otros.

37. Alejandro Rabinovich sostiene que la dicotomía de bandos para referirse a posición política de soldados durante la independencia puede ser interrogada, puesto que "los actores armados ocuparon posiciones móviles y asociaciones cambiantes". Rabinovich, A., Ser Soldado, Op. Cit., L 112.

38. ACC, Popayán, Colombia, Independencia, J 1, Cr 3, Sig. 5193, f. 7r-v.

39. ACC, Popayán, Colombia, Independencia, J 1, Cr 3, Sig. 5193, f. $5 \mathrm{v}$.

40. ACC, Popayán, Colombia, Independencia, J 1, Cr 3, Sig. 5193, f. $5 \mathrm{v}$.

41. ACC, Popayán, Colombia, Independencia, J 1, Cr 3, Sig. 5193, f. 7r.

42. ACC, Popayán, Colombia, Independencia, J 1, Cr 3, Sig. 5193, f. 2 r.

43. ACC, Popayán, Colombia, Independencia, J 1, Cr 3, Sig. 5193, f. $3 \mathrm{v}$.

44. ACC, Popayán, Colombia, Independencia, J 1, Cr 3, Sig. 5193, f. 36r.

45. Veáse: Dueñas, Guiomar, "Adulterios, amancebamientos, divorcios y abandono: La fluidez de la vida familiar santafereña, 1750-1810", Anuario Colombiano de Historia Social y de la Cultura, Bogotá, n²3, 1996; Dueñas Guiomar, Los Hijos del Pecado: ilegitimidad y vida familiar en la Santafé de Bogotá colonial, 1750-1810, Universidad Nacional, Bogotá, 1997; Rodríguez, Pablo, Seducción, amancebamiento y abandono en la Colonia, Fundación Simón y Lola Guberek, Bogotá, 1991; Rodríguez, Pablo, Sentimientos y vida familiar en el Nuevo Reino de Granada Siglo XVIII, Ariel, Bogotá, 1997; Rodríguez, Pablo, “Matrimonio incestuoso en el Medellín colonial, 1700-1810”, Revista de Extensión Cultural de la Universidad Nacional de Colombia, Bogotá, n²4, 1998; Tovar Pinzón, Hermes, La batalla de los sentidos: infidelidad, adulterio y concubinato a fines de la Colonia, Ediciones Uniandes, Bogotá, 2012; Tascón, Lida Elena, Sin temor de Dios ni de la real justicia: Amancebamiento concubinato y adulterio en la Gobernación de Popayán, 1760-1810, Tesis de maestría en Historia, Universidad del Valle, Cali, Colombia, 2014; Plata, William y Mendieta, Santiago, "Delitos sexuales y contra la familia en el nororiente del Virreinato de la Nueva Granada, 1774-1810. De la norma a la aplicación", Historia y Espacio, Cali, vol. 15, n52, 2019, p. 109-136.

46. Aunque los trabajos sobre amistades ilícitas en Colombia han cubierto el período colonial tardío hasta 1810, no hay razón para pensar que las relaciones ilícitas simplemente desaparecieron durante las guerras. Esas relaciones siguieron judicializándose aún en un periodo tan turbulento de transición política y cambio jurídico. Eso sí, al parecer, las motivaciones para criminalizar cambiaron y tomaron otros matices todos relacionados con el contexto de guerra y conflicto por el poder durante la independencia. Pérez-Villa, Ángela, Disorderly Love: Illicit Friendships, Violence, and Law in a Slave Society at War, Popayan-Colombia, 1809-1830, Tesis de doctorado en Historia y Estudios de la Mujer, University of Michigan, EEUU, 2017. 
47. ACC, Popayán, Colombia, Independencia, J 1, Cr 3, Sig. 5193, f. 9r.

48. Salinas, René, "Las otras mujeres: madres solteras, abandonadas y viudas en el Chile tradicional (siglos XVIII-XIX)", en Fermandois, Joaquín \& Stuven, Ana María, Historia de las mujeres en Chile, Tomo 1, Taurus, Santiago de Chile, 2011, p. 181. Ver también: Ramírez, María Imelda, Las mujeres y la sociedad colonial de Santa Fe de Bogotá, 1750-1810, Instituto Colombiano de Antropología e Historia, Bogotá, 2000; McCaa, Robert, "La viuda viva del México borbónico: Sus voces, variedades y vejaciones," en Gonzalo Aizpuru, Pilar (ed.), Familias novohispanas: siglos XVI al XIX, El Colegio de México, Ciudad de México, 1991, p. 299-324.

49. Lux, Martha, Las mujeres de Cartagena de Indias en el siglo XVII: Lo que hacían, les hacían y no hacían, y las curas que les prescribían, Universidad de los Andes, Bogotá, 2006, p. 25-27; Rodríguez, Pablo, "La familia en Colombia", en Rodríguez, Pablo, La familia en Iberoamérica 1550-1980, Universidad Externado de Colombia, Bogotá, 2004, p. 246-289; Rodríguez, Pablo, "Las hojas del otoño: ancianos y viudos del siglo XVIII neogranadino", Historia Crítica, Bogotá, n¹1, 1995, p. 53-62; Vélez, Luz Amparo \& Vargas, Eunice \& Ojeda, Norma, "Jefatura femenina y estratificación sociorracial en Cali, 1797-1807”, Secuencia [En línea], Ciudad de México, n95, 2016, p. 6-38.

50. Albornoz Vásquez, María Eugenia, "La injuria de palabra en Santiago de Chile, 1672-1822", Nuevo Mundo Mundos Nuevos [En Línea], Coloquios, Puesto en línea el 07 febrero 2005, Párrafo 15, URL: http://nuevomundo.revues.org/240

51. Víctor Uribe-Urán indica que, para fines de la colonia, de los 130 letrados en la Nueva Granada, nueve vivían en la región suroccidente. Los números pudieron ser más altos, pero es lo que estima con base en sus fuentes. Este autor también denota que las excusas de los letrados para evadir ser asignados a casos legales indeseables, como servir de abogados de pobres, fueron comunes y en ocasiones ridículas. Uribe-Urán, Víctor, “The Lawyers and New Granada's Late Colonial State", Journal of Latin American Studies, vol. 27, n³, 1995, p. 525-527.

52. ACC, Popayán, Colombia, Independencia, J 1, Cr 3, Sig. 5193, f. $24 \mathrm{r}$.

53. ACC, Popayán, Colombia, Independencia, J 1, Cr 3, Sig. 5193, f. 36v.

54. ACC, Popayán, Colombia, Independencia, J 1, Cr 3, Sig. 5193, f. $18 \mathrm{r}$.

55. ACC, Popayán, Colombia, Independencia, J 1, Cr 3, Sig. 5193, f. 18 r.

56. ACC, Popayán, Colombia, Independencia, J 1, Cr 3, Sig. 5193, f. 18v.

57. ACC, Popayán, Colombia, Independencia, J 1, Cr 3, Sig. 5193, f. 20 r.

58. ACC, Popayán, Colombia, Independencia, J 1, Cr 3, Sig. 5193, f. 19r.

59. ACC, Popayán, Colombia, Independencia, J 1, Cr 3, Sig. 5193, f. $25 \mathrm{v}$.

60. ACC, Popayán, Colombia, Independencia, J 1, Cr 3, Sig. 5193, f. 36v.

61. Cabe anotar que para el año de 1817 aparecen en el archivo casos relacionados a la junta de secuestros, tribunal creado por Morillo y Sámano, encargado de confiscar y expropiar los bienes de patriotas revolucionarios lo que indica que las autoridades fernandinas en Popayán también encontraron en el sistema judicial y en las cortes un espacio crucial para restablecer su poder. Para estudios sobre la junta de secuestros en particular, véase: Pita Pico, Roger "Los esclavos y las juntas de secuestros en los procesos de independencia de la Nueva Granada: entre la incertidumbre y la represión política," Anuario de Estudios Bolivarianos, Caracas, n¹9, 2012-2013, p. 135-73; Uribe-Urán, Víctor, Honorable Lives: Lawyers, Family, and Politics in Colombia, 1780-1850, University of Pittsburgh Press, Pittsburgh, 2000, p. 69.

62. Gaceta de Madrid, Madrid, $\mathrm{n}^{\circ} 30,1817$, p. 277-278.

63. Gutiérrez, D., La Restauración, Op. Cit., p. 62. Otras obras sobre el indulto en Colombia incluyen a: Melo Flores, Jairo Antonio. "El indulto en el proceso de Independencia de la Nueva Granada, 1808-1821." Revista Historia y Justicia, Santiago de Chile, n6, 2016; Ramírez Bacca, Renzo \& Ospina Echeverri, Marta, Cabildo, política y sociedad, 1810-1821. El caso de la provincia de Antioquia, Universidad Nacional de Colombia, Bogotá, 2011; Cuño Bonito, Justo, El retorno del Rey: El restablecimiento del régimen colonial en Cartagena de Indias, Universidad Jaume I, Castellón de la Plana, 2008. 
64. ACC, Popayán, Colombia, Independencia, J 1, Cr 3, Sig. 5193, f. 38r-v.

65. Melo Flores, J., "El indulto", Op. Cit.

66. En sus más recientes trabajos, Bianca Premo y Michelle McKinley abordan el rol de las mujeres en temas judiciales concernientes a la familia y a las relaciones interpersonales en Hispanoamérica en época colonial. Premo, Bianca, The Enlightenment on Trial: Ordinary Litigants and Colonialism in the Spanish Empire, Oxford University Press, New York, 2017 y McKinley, Michelle, Fractional Freedoms: Slavery, Intimacy, and Legal Mobilization in Colonial Lima, 1600-1700, Cambridge University Press, 2016.

\section{RESÚMENES}

La restauración monárquica española en la Nueva Granada entre 1815 y 1819 constituyó un periodo de transición violenta que ha sido ampliamente estudiado desde un enfoque políticomilitar. Este artículo propone expandir nuestra comprensión del periodo indagando sobre aspectos socioculturales y legales, a partir de fuentes judiciales. Con este fin, se examina meticulosamente un expediente criminal por el homicidio de un "negro libre" en 1815, proceso que, al permanecer activo durante tres años, dejó un sustancioso registro sobre la vida cotidiana en Popayán, una provincia esclavista. La atención a los detalles permite reconstruir los espacios de socialización entre la gente del común y ahondar en la administración de justicia mientras se expone el potencial analítico de estas fuentes.

The Spanish monarchical restoration in New Granada between 1815 and 1819 constituted a period of violent transition that has been widely studied from a political-military perspective. This article proposes to expand our understanding of the period by inquiring about the sociocultural and legal dimensions through judicial sources. To this end, the author meticulously examines a criminal case about the murder of a "free Black man" in 1815, which, after remaining open for three years, left a substantial record of daily life in Popayán, a slave-owning province. Attention to detail allows for the reconstruction of socialization practices among common people and to analyze the administration of justice while exposing the potential of these sources.

La restauration monarchique espagnole en Nouvelle-Grenade entre 1815 et 1819 a constitué une période de transition violente qui a été largement étudiée d'un point de vue politico-militaire. Cet article propose d'élargir notre compréhension de cette période en s'interrogeant sur les dimensions socioculturelles et juridiques à travers des sources judiciaires. À cette fin, l'auteur examine minutieusement une affaire pénale concernant le meurtre d'un "Noir libre" en 1815, qui, après être restée pendante pendant trois ans, a laissé une trace substantielle de la vie quotidienne à Popayán, une province esclavagiste. Le souci du détail permet de reconstituer les pratiques de socialisation des gens ordinaires et d'analyser l'administration de la justice tout en exposant le potentiel de ces sources. 
ÍNDICE

Keywords: monarchical restoration, independence, Popayán, New Granada, daily life, criminal records

Palabras claves: restauración monárquica, independencia, Popayán, Nueva Granada, vida cotidiana, juicios criminales

Mots-clés: restauration monarchique, independance, Popayán, Nouvelle-Grenade, vie quotidienne, archives criminelles

\section{AUTOR}

\section{ÁNGELA PÉREZ VILLA}

Doctora en Historia y Estudios de la Mujer, University of Michigan, Ann Arbor, EE. UU. Profesora Asistente de Historia, Western Michigan University, EE. UU. Correo electrónico: angela.perezvilla@wmich.edu.

El presente artículo deriva de la investigación archivística para su tesis doctoral, la cual contó con apoyo financiero de la Escuela de Posgrados de University of Michigan. Una versión preliminar de este artículo fue presentada en el Congreso Internacional de Americanistas, eje temático "Las fuentes judiciales en el Americanismo", en la Universidad de Salamanca, España, en 2018 con el patrocinio financiero de Rollins College, donde la autora realizó una estancia posdoctoral. 